\title{
Acquired cystic disease of kidney with multiple renal and urothelial neoplasms
}

\author{
SS BANERJEE, M HARRIS, EW LUPTON, ${ }^{*}$ P ACKRILL $\dagger$ \\ From the Departments of Histopathology, ${ }^{*}$ Surgery, and $\nmid$ Renal Medicine, Withington Hospital, Manchester
}

SUMMARY Acquired polycystic disease with concurrent development of renal cell tumours is a well documented complication of long term haemodialysis. We present a case of acquired polycystic disease with renal cell tumours and multifocal urothelial tumours. Only two similar cases have been recorded.

Patients receiving long term haemodialysis sometimes develop multiple renal cysts, which can simulate an adult type of congenital polycystic disease. Dunnill et al coined the term "acquired cystic disease of the kidneys" for this condition.' In some cases it is further complicated by the development of renal adenomas or carcinomas, or both. We report a case of acquired polycystic disease with associated renal cell tumours and multifocal caliceal, ureteric, and vesical transitional cell carcinomas. This is the third recorded case of urothelial neoplasia associated with acquired polycystic disease.

\section{Patients and methods}

\section{CASE REPORT}

The patient was a 56 year old white man who in 1963 , at the age of 35 , developed an acute nephritic illness. He was treated symptomatically, and no renal biopsy was performed. Subsequently, he developed pronounced proteinuria with hypertension; his renal function deteriorated over the next six years and chronic renal failure ensued. In 1972 regular intermittent haemodialysis was started. In 1978 a parathyroidectomy was performed to alleviate severe secondary hyperparathyroidism. He was given a renal allograft into the left iliac fossa in 1979 , but within a few weeks the transplanted kidney had to be removed.

In 1983 he was readmitted for investigation of a two month history of haematuria. Cystoscopy showed a small papillary tumour on the left posterolateral wall of the urinary bladder, which was resected; histological examination showed a grade I non-invasive papillary transitional cell carcinoma. His haematuria persisted, and he complained of pain in the right lower abdomen. Right retrograde ureteropylography and a brush biopsy of the right ureter were carried out, and the brush biopsy sinowed a papillary transitional cell carcinoma (grade III). In 1984 he underwent a right nephroureterectomy.

\section{Results}

MACROSCOPIC APPEARANCE

The nephrectomy specimen weighed $209 \mathrm{~g}$ and measured $11 \times 7 \times 5 \mathrm{~cm}$. The attached ureter was $25 \mathrm{~cm}$ long. The external and cut surfaces of the kidney showed numerous thin walled cysts $(0 \cdot 2-$ $2.5 \mathrm{~cm}$ in diameter) throughout the cortex and medulla (Fig. 1). The appearance of the specimen was reminiscent of an adult type of congenital polycystic kidney, though the kidney was not greatly enlarged. Some of the cysts contained haemorrhagic fluid and chocolate coloured blood clots. Pronounced destruction of the renal parenchyma with compensatory hyperplasia of peripelvic fatty tissue was visible. The pelvicaliceal system seemed to be dilated. Three small grey-white nodules like plaque $(0.2-0.5 \mathrm{~cm}$ in diameter) were present within the cystic spaces. The ureter contained two friable nodules, each about $1.5 \mathrm{~cm}$ in diameter, which partially occluded the lumen. These nodules were $7.5 \mathrm{~cm}$ and $10.0 \mathrm{~cm}$ from the pelviureteric junction.

\section{MICROSCOPIC FEATURES}

The cysts seemed to comprise dilated tubules and were lined by single layers of cuboidal to columnar epithelium. In a few the internal epithelium showed cellular atypia (Fig. 2). The intervening renal tissue comprised atrophic tubules, fibrous tissue, thick walled blood vessels, and a few mononuclear 


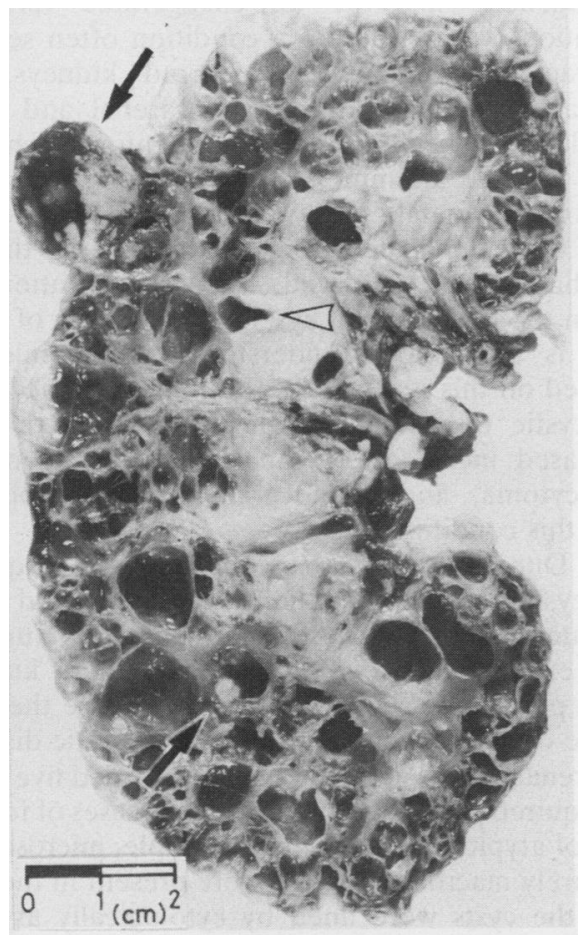

Fig. 1 Acquired polycystic kidney. Arrows point to adenomata (peripheral), and arrowhead indicates small urothelial tumour similar to plaque in one calix. inflammatory cells. Abundant crystals of oxalate and foci of calcification were present. No glomeruli were seen. Many cysts contained haemorrhagic fluid, and a few showed papillary microadenomas.

The largest tumour, which was visible macroscopically, was composed of rather uniform cells with abundant eosinophilic cytoplasm, vesicular nuclei, and small but conspicuous nucleoli. The cells were mostly arranged in tubules and trabeculae, but a few papillary formations were also noted (Fig. 3). A large amount of iron was present within the epithelial cells and was presumably due to old intracystic haemorrhage. No mitotic activity was seen. It was impossible to assess the malignant potential of this tumour. The two other nodules similar to plaque were grade II transitional cell carcinomas arising from the calices (Fig. 4). The ureteric tumours were also urothelial carcinomas of a similar grade. No invasion of the muscle wall had occurred.

\section{Discussion}

Acquired polycystic disease is a well documented complication of long term intermittent haemodialysis. ${ }^{1-4}$ One case has also been reported in a patient with chronic renal failure who developed acquired polycystic disease with renal cell carcinoma before he started maintenance haemodialysis. ${ }^{2}$ The

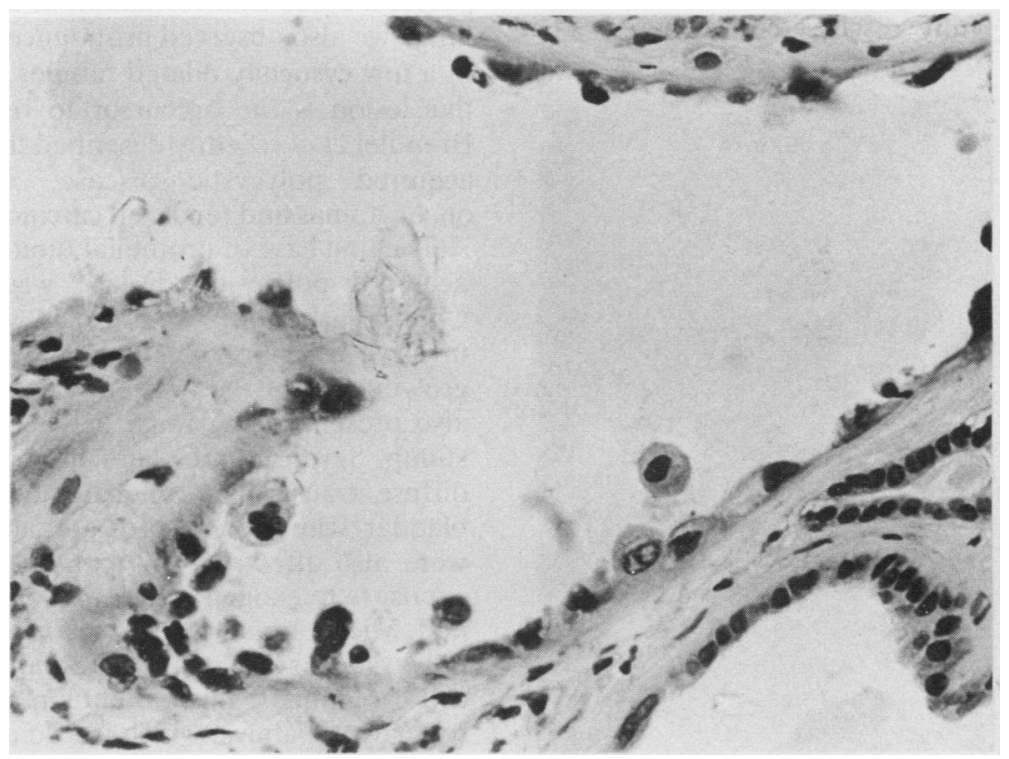

Fig. 2 Cyst lined by atypical epithelial cells showing nuclear hyperchromatism and pleomorphism. Oxalate crystals are present within lumen. $\times 360$. (Haematoxylin and eosin.) 


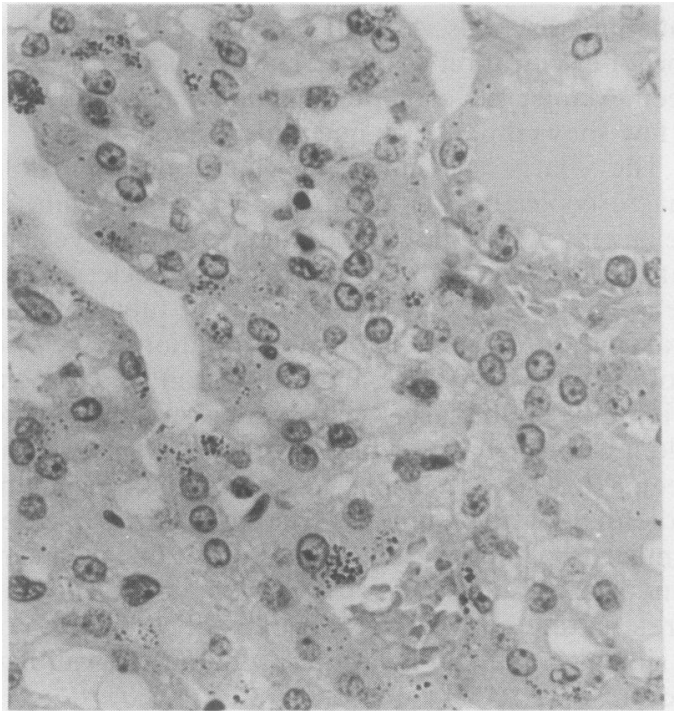

Fig. 3 Renal cell tumour with trabecular and glandular pattern. Several cells contain granules of haemosiderin. $\times$ 360. (Haematoxylin and eosin.)

concurrent development of renal tumours was reported by Dunnill et al in the initial description of the condition, ${ }^{1}$ and later by others. ${ }^{235}$ Recently, two separate case reports described the development of urothelial tumours in acquired polycystic disease. ${ }^{24}$

The precise pathogenesis of acquired polycystic disease is still uncertain, but the probable mechanisms have been fully discussed elsewhere. ${ }^{5}$ The

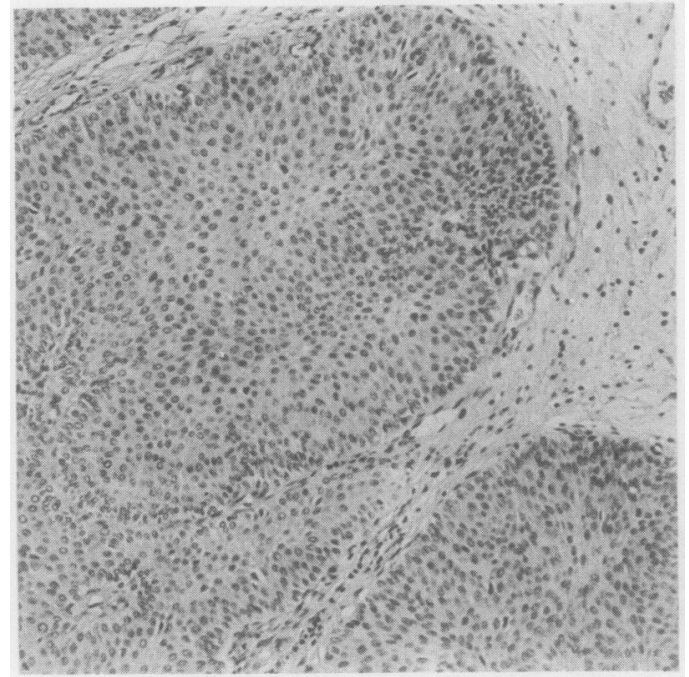

Fig. 4 Transitional cell carcinoma in calix. $\times 230$. (Haematoxylin and eosin.) pathogenesis may be an exaggerated form of retention cyst formation, a condition often seen in contracted, granular, and scarred kidneys. An increased incidence of both extrarenal and renal neoplasia has been reported in patients with chronic renal failure. ${ }^{6}$ Immune suppression and accumulation of toxic metabolites with carcinogenic potential have been implicated in the pathogenesis, though this has not been proved. The exact relation between the formation of cysts and neoplasia of renal cells is also poorly understood, and opinion is divided on this issue. ${ }^{37}$ All the reports on acquired polycystic disease do suggest, however, that an increased incidence of renal tumours (adenoma, oncocytoma, and adenocarcinoma) is associated with this condition.

In Dunnill et al's series of 14 cases of acquired polycystic disease six patients had associated renal cell tumours, of which one was malignant.' Hughson et al examined 66 end stage renal failure kidneys from patients receiving dialysis to analyse the incidence of atypical cysts, acquired polycystic disease, and renal cell adenomata. ${ }^{3}$ They recorded five cases of acquired polycystic disease and 20 cases of formation of atypical cysts in which multiple, microscopic, or barely macroscopic cysts were present in the cortex (the cysts were lined by cytologically atypical proliferative epithelium). There was also a significant increase in the incidence of adenomas in those patients with cysts. They therefore concluded that "the stimulus for neoplastic growth accompanies a cystic transformation of kidneys." Interestingly, we also observed pronounced cellular atypism in a few cystically dilated tubules, and, presumably, this lesion is the precursor to renal cell tumours. Brendler $e t$ al recently described three more cases of acquired polycystic disease; in two patients oncocytomas and renal cell carcinomas were found. ${ }^{5}$

The tirst case of urothelial tumour associated with acquired polycystic disease was documented by Chung-Park et al. ${ }^{2}$ A multifocal, well differentiated, invasive transitional cell carcinoma was seen to be growing out of the cysts, and similar tumours were also present in the renal pelvis and in the ureteric stump. Seven months later the patient developed a diffuse transitional cell carcinoma of the urinary bladder. The ureters, prostate, and seminal vesicles were also affected. This patient had no history of exposure to exogenous urothelial carcinogens. Boon and Michael recorded a second case of acquired polycystic disease with pelvic and vesical transitional cell carcinoma ${ }^{4}$; this patient's renal failure was due to analgesic abuse, which is also an aetiological factor in urothelial neoplasia. ${ }^{8}$ The patients in both of these reports had renal cell tumours.

In our case the intrarenal transitional cell car- 
cinoma seemed to originate from the deformed calices, and similar tumours were also present in the attached ureter. Several microadenomas and one larger renal cell tumour of uncertain malignant potential were also seen. The patient denied having been exposed to aniline dyes or having taken excessive analgesics, both of which are aetiological factors in urothelial cancers.

The slowly increasing number of cases of urothelial cell tumours in acquired polycystic disease with coincidental renal cell tumours suggests that the association is not entirely fortuitous and that a common tumourogenic factor may have a role in the pathogenesis. The clinical implications of acquired polycystic disease have been emphasised in previous reports, but the additional complication of urothelial tumours exacerbates the problem. We therefore suggest that all patients receiving long term maintenance haemodialysis should be carefully followed up by cytological examination of urine at regular intervals; in suspected cases further clinical and radiological investigations are mandatory.

We thank Dr Alan Curry for the photography and Mrs CF Shaw for typing the manuscript.

\section{References}

' Dunnill MS. Millar PR. Oliver D. Acquired cystic disease of the kidneys: a hazard of long term intermittent maintenance haemodialysis. J Clin Pathol 1977;30:868-77.

${ }^{2}$ Chung-Park M. Ricanti E. Lankerani M. Kedia K. Acquired renal cysts and multiple renal cell and urothelial tumours. $\mathrm{Am}$ $J$ Clin Pathol 1983;79:238-42.

${ }^{3}$ Hughson MD. Hennigar GR. McManus JFA. Atypical cysts, acquired renal cystic disease, and renal cell tumours in end stage dialysis kidneys. Lab Invest 1980:42:475-80.

4 Boon NA. Michael J. Multiple neoplasia in a patient on dialysis presenting with haematuria. Br J Urol 1984;56:96-7.

'Brendler CB. Albertsen PC. Goldman SM. Hill GS. Lowe FC, Millan JC. Acquired renal cystic disease in the end stage kidney: urological implications. J Urol 1984; 132:548-52.

- Miach PJ. Dawborn JK. Xipell J. Neoplasia in patients with chronic renal failure on long-term dialysis. Clin Nephrol 1976;5: 101-4.

' Bennington JL, Beckwith JB. Tumours of the kidney, renal pelvis and ureter. In: Firminger HI, ed. Atlas of Tumour Pathology. 2nd series, Fascicle 12. Washington DC: Armed Forces Institute of Pathology, 1975:96-8.

" Bengtsson U. Johansson S. Angervall L. Malignancies of the urinary tract and their relation to analgesic abuse. Kidney Int 1978; 13: 107-13.

Requests for reprints to: Dr SS Banerjee, Department of Histopathology, Withington Hospital, Nell Lane, Manchester M20 8LR 